\title{
LAS CRÓNICAS DE JOSÉ MARTÍ Y EL ORIGEN DEL PERIODISMO MODERNO LATINOAMERICANO*
}

\section{Eduardo Santa Cruz Achurra*}

\begin{abstract}
Resumen
A fines del siglo XIX se produce un cambio fundamental en la prensa latinoamericana. El "modelo informativo" dejaba atrás a la "prensa doctrinaria", predominante desde la Independencia, asociado al nacimiento del mercado informativo y de los géneros periodísticos modernos y relacionado con el proceso de autonomización del campo intelectual en general, lo que provocó la presencia de un nuevo tipo de escritor que encontró en la prensa y en la crónica un espacio de desarrollo, no exento de tensiones. Este texto analiza estos procesos a partir del caso de José Martí y su trabajo periodístico desde Nueva York para diarios latinoamericanos.
\end{abstract}

Palabras Clave: Historia Prensa Latinoamericana, Modelos de prensa, Prensa informativa moderna, Crónica periodística, José Martí.

\section{The Chronicles of José Martí AND THE ORIGIN OF MODERN LATINAMERICAN JOURNALISM}

\begin{abstract}
At the end of the 19th century a fundamental change occurs in the Latinamerican press. The "information model" left behind "doctrinal press", predominantly from independence, associated with the birth of the market information and journalistic genres related to the process of empowerment of the intellectual field and modern in general, causing the presence of a new type of writer who found a space of development in the press and in the Chronicle not free of tensions. This text discusses these processes from the case of José Martí and his journalistic work from New York to Latinamerican journals.
\end{abstract}

Keywords: Latinoamerican Press History, Press Model, Liberal Modern Press, Journalism Chronicle, José Martí.

Recibido: 08-04- 2014Aceptado: 14-01-2015

\footnotetext{
* El presente texto se inscribe al interior de una investigación más amplia y de mayor alcance, como fue el proyecto Espacio público y subjetividad en América Latina: Bello, Dario y Martí, financiado por el Fondo Nacional de Ciencia y Tecnología (FONDECYT) con el No 1085029 , y en la que el autor se desempeñó como coinvestigador.

** Chileno. Periodista. Diplomado en Investigación en Comunicación Social, Instituto de Comunicación e Imagen, Universidad de Chile. Santiago, Chile. esantacr@uchile.cl
} 


\section{Introducción}

En la investigación titulada Espacio público y subjetividad en América Latina: Bello, Darío y Martí se planteó examinar dos dispositivos culturales propios del siglo XIX en América Latina, razón por la que este artículo forma parte de ella a modo de resultado. De dicho trabajo se ha rescatado que, en primer lugar, la dimensión proyectual o fundacional que caracteriza la obra de Andrés Bello y, en segundo lugar, las tensiones o desencuentros que, en relación con el mundo moderno, caracterizan obras como los trabajos periodísticos de José Martí y Rubén Darío, donde interesa ver el modo como la modernidad deja de ser primariamente "proyecto" para devenir sobre todo "experiencia".

En esta perspectiva interesaba destacar las diversas reorganizaciones que se han dado en el campo de la producción simbólica y estética en América Latina, modificando sus paisajes culturales o públicos, por medio de cartografiar "espacialidades" (compuestas por temas, medios expresivos, inflexiones lingüísticas, escritores y públicos) como también las cambiantes relaciones entre los campos de la cultura y del poder. La investigación se alimentó precisamente de estas aperturas y de unas diligencias metodológicas sensibles al estudio de los factores comunicacionales, expresivos y públicos.

De esta forma, demarcándose de una pretensión de totalidad o epocal, más cerca de unos "acontecimientos", o de unas determinadas redes o cristalizaciones histórico-culturales, los análisis buscaron hacerse cargo de unos determinados emplazamientos comunicacionales y subjetivos: la res publica litterarum en Bello y el tópico de la "experiencia" en los escritores modernistas, para decirlo brevemente.

En dicho marco, la investigación específica de la que se nutre el presente texto tenía como objetivo resolver la interrogante acerca de si los trabajos que Martí publicó en diversos diarios latinoamericanos, se inscribían en el proceso de transformaciones que vivió la prensa a fines del siglo XIX o, más bien, se explican por la llamada "autonomización" del campo literario en la región.

La hipótesis que articuló la investigación y este texto, es que la figura del Martí cronista está más cerca del rol que, en la segunda mitad del siglo XIX, desarrolló la figura del Corresponsal y que, por tanto, Martí contribuyó de manera importante, junto a otros literatos y emergentes 
periodistas profesionales, a la consolidación de la crónica periodística como género dotado de una singularidad.

Para ello, y como un modo de patentizar las objetividades que sustentan los emplazamientos que interesaba describir, así como las diferencias que en estos planos se dan con otros modelos y prácticas, se buscaba destacar no tan sólo los contenidos o tópicos que publicitan estos medios sino también, o principalmente, sus propias condiciones o pautas discursivas. Un tipo de aproximación, menos atenta a lo que los discursos ocultan, o a su subsuelo, y más pendiente de deslindar o cartografiar exterioridades o positividades. La perspectiva analítica que orientó el acceso a las fuentes, concibe los materiales no como expresión de unas invariantes lógicas, al modo de un cierto estructuralismo, sino antes bien como unas articulaciones o acontecimientos preñados de historicidad y cambios.

Metodológicamente, se examinaron todas las crónicas contenidas en las Escenas Norteamericanas y redactadas por José Martí en Nueva York a partir de 1881, desde "las entrañas del monstruo", según sus palabras, para ser publicadas en diversos periódicos latinoamericanos. Se trata de un conjunto de 177 artículos recopilados en cuatro volúmenes que suman 1.965 páginas de las Obras Completas del autor (1992), ocupando desde el volumen 9 al 12, ambos inclusive. Como se sabe, dichos trabajos fueron encargados por diversos periódicos de América Latina, destacando el caso de La Nación, de Buenos Aires, donde se publicaron 133 de ellos (Ramos 1989).

Otros destinos significativos fueron las páginas de $\mathrm{La}$ Opinión Nacional, de Caracas, donde se publicaron 24 entre 1881 y 1882, El Partido Liberal, de México, donde se publicaron ocho artículos y La Opinión Pública, de Montevideo, con otros cinco. Los siete restantes fueron publicados en La América, que se editaba en la propia Nueva York. Hubo varias reproducciones o, directamente copias, de estos textos en otros periódicos de la región. Es el caso de Chile, donde hay numerosas publicaciones de textos publicados antes por La Nación, de Buenos Aires. En la recopilación efectuada por Jorge Benítez sobre la presencia de las crónicas martianas publicadas en Chile, se reproducen 37 de las 70 que este autor pudo rastrear en la prensa chilena entre 1881 y 1895 (Benítez 1995). De ellas, 22 habían sido publicadas antes en el diario bonaerense. En total, 44 aparecieron en La Época; 15 en El Mercurio de Valparaíso; 6 
en La Libertad Electoral: 4 en El Ferrocarril y uno en El Sur de Concepción. Cabe, sin embargo, advertir que aparecen otras quince no consignadas en las Obras Completas antes citadas y publicadas en diversos periódicos chilenos.

\section{La autonomización de los géneros periodísticos}

En la segunda mitad del siglo XIX, la prensa latinoamericana vio aparecer las primeras manifestaciones de un nuevo modelo periodístico que desplazó a la prensa doctrinaria predominante durante la mayor parte de la centuria, desde el proceso independentista en adelante (Santa Cruz, 2009). A la creciente configuración de un público lector masivo se unió un conjunto de innovaciones tecnológicas que se sucedieron unas a otras, tales como la imprenta a vapor, el telégrafo, los cables submarinos, la linotipia y, a finales de siglo, el teléfono y el uso de la electricidad, los que ligados a los nuevos medios de transporte como la navegación a vapor y el ferrocarril, crearon las condiciones para que emergiera una nueva forma de hacer periodismo dedicada ahora a "recoger las noticias, aumentar el número de páginas, hacer frente a las mayores tiradas. No se limitó a estas transformaciones materiales; fue necesario adaptar la prensa a las necesidades y a los gustos del público" (Weill 173). Por otra parte, junto a las noticias, comenzó el uso de la ilustración y la fotografía y también apareció paulatina, pero crecientemente el aviso publicitario, el que, en un sistema de prensa de mercado, constituye el mecanismo fundamental para la permanencia y éxito del negocio.

La prensa liberal moderna naciente se definió a si misma por su pretensión informativa y, consecuente con ello, por la generación de un mercado noticioso y de empresas suficientemente capaces para competir en él y desarrollarlo. La innovación tecnológica fue causa y efecto de lo anterior. La difusión y propagación doctrinaria, característica de la primera mitad del siglo XIX, e incluso la simple opinión se supondrían cada vez más relegadas a la página editorial. La prensa liberal moderna se volcó así hacia un periodismo informativo enfocado hacia la primicia noticiosa, además inserta y determinada por las reglas de la competencia y el mercado. Estas tendencias universales se manifestaron en la prensa de América Latina en las últimas décadas del siglo XIX, con mayor fuerza y prontitud en unos países que en otros, lo que estaba generalmente determinado por los particulares contextos de cada uno de ellos. Ello significó que la aparición de la prensa informativa y de empresa se 
expresara como una tendencia que se desarrolló a lo largo de varias décadas y, por tanto, el campo periodístico, por ella desarrollado, asumió, en general, un perfil complejo y heterogéneo donde confluyeron diversos modelos de prensa y en el que la prensa doctrinaria predominante se mantuvo presente incluso hasta principios del siglo $X X$, en algunos lugares, mientras paulatinamente iba dejando su lugar a la prensa liberal informativa moderna.

El ámbito de la crónica se constituyó en el período analizado, en un espacio de emergencia de un nuevo tipo de discurso y producción intelectual. En esa perspectiva, nos interesa destacar un doble rol de la crónica periodística, en tanto barómetro de los tiempos y en cómo va dando cuenta de las transformaciones modernizadoras en las claves de la vida cotidiana, desde su experiencia, en el sentido que Berman (1990) le da al concepto. En la dirección señalada ubicaremos el análisis de las crónicas de José Martí.

Lo anterior nos permite afirmar la intuición de que las Escenas Norteamericanas son fundamentalmente textos periodísticos, destinados a un público lector de periódicos, si bien ilustrado, no por ello menos interesado en el acontecer cotidiano. Martí va ofreciendo a lo largo de los años tanto la información como la interpretación, más o menos profunda, del desarrollo de la actualidad de la sociedad norteamericana. En la medida en que dicho trabajo se prolongó durante años, a través de sus textos es posible percibir dichos procesos en su devenir.

Lo dicho apunta a la condición y estatuto del autor, en tanto sujeto enunciador y de sus textos. La mayoría de la frondosa bibliografía que se ha ocupado en los últimos años del análisis de esta parte de la obra de Martí, lo ha hecho desde la, por cierto legítima, preocupación por los procesos de constitución conflictiva y relativamente autónoma del campo literario en América Latina, a fines del siglo XIX, en el contexto de la aparición de lo que luego se denominaría como modernismo literario, destacando en ello el citado Ramos y Susana Rotker (1992, 2005). De este modo, se adscriben estos trabajos periodísticos de Martí al campo de lo literario, sin más, incluso cuando aparece una cierta polémica a la hora de caracterizar la naturaleza de sus escritos para los periódicos latinoamericanos. En ese sentido, por ejemplo, Schulman (2002) se hace cargo de la existencia de dicha polémica, pero la soluciona a partir de colocar la interrogante en el terreno de los géneros literarios, afirmando que: 
Si aceptamos la distinción que establece White entre "anales", "crónicas" e "historias", se disuelve la debatida problemática de definir el género literario de la escritura martiana, sobre todo las de sus "crónicas" (¿son ensayos o crónicas?, ¿son crónicas las cartas?), pues obviamente los textos agrupados bajo el rótulo de "Escenas norteamericanas", más otros escritos dispersos de la misma temática, pertenecen genéricamente a la “crónica". (53)

Lo que muchos de estos autores no consideran es la posibilidad de que los artículos publicados por Martí en periódicos latinoamericanos, fueran precisamente y antes que nada textos periodísticos, los que cuentan con ciertas especificidades narrativas y específicas estrategias escriturales, las que justamente están despuntando a fines del siglo XIX, contribuyendo de esta forma a la generación de un campo periodístico, también dotado de relativa autonomía.

En ese sentido, la discusión relativa a la naturaleza de los trabajos martianos para periódicos, es posible situarla al interior de la emergencia de dicho campo y de la naturaleza de los géneros periodísticos, es decir, de su relación con la transformación que vive la prensa occidental desde mediados del siglo XIX. Los géneros -entendidos como herederos de los géneros literarios- satisfacen en la actividad periodística una necesidad inmediata y urgente, cual es la de facilitar el trabajo colectivo, todo lo cual está a la base del surgimiento de un profesional determinado, diestro en el manejo de técnicas de selección y producción de informaciones. Por ello, pareciera más útil la conceptualización instalada por Martín Barbero y Muñoz (1992), que concibe al género ante todo como una estrategia de comunicabilidad, es decir, más allá de la noción de sustrato linguístico que lo definía clásicamente como un principio de coherencia textual y una forma de clasificación, dicho autor lo caracteriza como algo que pasa por el texto y no sólo algo que pasa en el texto.

Dicha noción de género apunta preferentemente a los modos en que se hacen reconocibles y organizan la competencia comunicativa los destinadores y los destinatarios. En esa perspectiva, Martín Barbero y Muñoz agregan que la consideración de los géneros como un hecho puramente literario o su reducción a moldes prefijados para la fabricación o etiquetación de textos, habría impedido comprender la verdadera función del género en la competencia narrativa de los espectadores. 
Así, entonces, el género puede ser entendido como una estrategia de comunicación configurada por prácticas de enunciación de unos sujetos (situados tanto del lado de la producción como del consumo/ reconocimiento) y por formatos de sedimentación de unos saberes, unos hábitos y unas técnicas.

Por otra parte, vista desde la reflexión y la práctica actuales de la prensa moderna, la crónica periodística aparece como uno de los géneros más difícilmente clasificable. Sin embargo, su vigencia (aunque relegada a planos secundarios por otros géneros como el informativo y el reportaje interpretativo) obliga a que diversos autores hayan intentado definirla (Martínez Albertos, 1974). Entre todas pareciera más fecunda desde el punto de vista de su operacionalidad analítica, la visión que asume como punto de partida una cierta ambiguedad, que de alguna forma incorpora la maleabilidad del género, estableciendo que se trata de un género informativo, pero que es algo más que pura información y algo menos que un reportaje interpretativo (Martin Vivaldi, 1993).

En el caso de la crónica periodística la libertad estilística tendría un sólo límite fundamental establecido por el carácter noticioso del hecho en torno al cual se escribe, ya que como vimos, allí estaría la clave específica de su identidad, en tanto forma periodística y no literaria. Este límite, sin embargo, no se restringe al plano del contenido, sino que se manifiesta con similar importancia en el plano expresivo, el cual debe someterse a las exigencias comunicativas, a la presencia heterogénea del lector, en sentido amplio, lo que cuestiona visiones como la de Susana Rotker acerca de "que se dedica a los hechos menudos y cuyo interés central no es informar sino divertir" (2005: 103).

Así, el estilo de la crónica ha de ser claro, sencillo, conciso; revelador de un contenido objetivo que se comunica a alguien. En ese marco, valen todos los recursos estilísticos y retóricos: comparación, metáfora, ironía, paradoja e incluso, aunque mesuradamente, la hipérbole. La única exigencia que fluye del marco es la claridad comunicativa en función de un público determinado. En definitiva, toda crónica tiene un sentido y entraña una significación: se escribe de algo y por algo o para algo; se cuenta un hecho significativo y se le da al relato un sentido estimativoaxiológico; se narra un suceso y se procura describir su valor. En definitiva, y aplicado a los trabajos martianos, se trata de poner de relieve lo que podemos llamar el "valor periodístico e informativo" de la crónica 
o el artículo, antes que su posible "valor literario", en el entendido obvio que ambos no son, necesariamente, incompatibles.

\section{Lo que cuentan las Escenas...}

Al analizar las Escenas Norteamericanas, se puede advertir que la temática central de los artículos es la política norteamericana, presente en cerca de 70 trabajos. En cada uno de los volúmenes no hay menos de un tercio de los artículos reproducidos que no tengan por tema, muchas veces exclusivo, el desarrollo de la actividad política estadounidense, entendida ésta como lo relacionado con la actividad del gobierno y el Parlamento y de la vida de los partidos principales, republicanos y demócratas, es decir, del sistema político y las elecciones periódicas, informando en detalle de su funcionamiento y conflictos.

Hay una evidente intención por mostrar tanto los mecanismos y procedimientos de un régimen liberal democrático consolidado después de pasadas dos décadas desde la guerra civil (Martí, 1992, Vol. 10: 93101; Vol. 11: 409-417 y Vol. 12: 41-51) ${ }^{1}$, cuanto también los vicios e imperfecciones que, de alguna forma, expresaban el desarrollo de un sentido común y una mentalidad propias de un capitalismo emergente, en términos de corrupción política, abusos de poder en medio del predominio de un individualismo y utilitarismo exacerbado (Martí, 1992, Vol. 11: 435-443) $)^{2}$

Tal vez, por ello mismo, el tema que Martí privilegia a continuación es lo que se podría clasificar como "costumbres y vida cotidiana", lo que se relaciona con formas de vida, oficios y experiencia de la ciudad, con cerca de 40 textos, cuya mayor cantidad se concentra en los dos últimos volúmenes, es decir de 1886 en adelante (Martí, 1992, Vol. 9: 199-213; Vol. 10:295-303; Vol. 11: 417-425)³. Lo antes dicho, no obstante, no fue obstáculo para que Martí lograra entregar un amplio y diverso panorama de una sociedad como la estadounidense de la época, en camino a constituirse muy pronto en la principal potencia capitalista mundial:

1 "El origen del Partido Republicano de los Estados Unidos", La Nación, Buenos Aires, 6 Noviembre 1884; "La presidencia de los Estados Unidos", La Nación, Buenos Aires, 22 Abril 1888; "La campaña electoral en los Estados Unidos", La Nación, Buenos Aires, 11 Octubre 1888.

2 "Cartas de Martí", La Nación, Buenos Aires, 26 Mayo 1888.

3 "Pascua y Santa Claus", La Opinión Nacional, Caracas, 6 Enero 1882; "Placeres y problemas de Septiembre", La Nación, Buenos Aires, 22 Octubre 1885 y "Nueva York bajo la nieve", La Nación, Buenos Aires, 27 Abril 1888, entre muchas otras. 
Martí fue el cronista hispanoamericano mejor informado sobre la vida y la cultura de Estados Unidos de los últimos decenios del siglo XIX. A diferencia de Rodó, por ejemplo, su conocimiento no era libresco ni, como en el caso de Sarmiento, el producto de una estancia de corta duración. Entre 1880 y 1895 vivió y trabajó en la ciudad de Nueva York; viajó a otras ciudades de la costa este del país, sobre todo a las de la Florida; leía y escribía inglés; y en los quince años de su residencia norteamericana adquirió un conocimiento envidiable de las costumbres, la idiosincrasia, la política, la tecnología, las artes plásticas, la música y la literatura de Estados Unidos. (Schulman 53)

En todo caso, si examinamos con mayor atención el panorama temático de las Escenas Norteamericanas, podemos encontrar ciertas características que van marcando distintos énfasis en la visión que Martí va elaborando de la sociedad estadounidense y de lo que considera necesario transmitir de ella al público bonaerense y latinoamericano, todo ello en un marco general amplio y variopinto desde el punto de vista temático. Así, es importante la presencia de los conflictos económico-sociales subyacentes y producto de los procesos de crecimiento y modernización. Alrededor de un $11 \%$ de los artículos se dedican parcial o exclusivamente al mundo sindical en formación, a huelgas y conflictos sociales y al desarrollo y presencia del ideario y movimientos socialistas y anarquistas emergentes (Martí, 1992, Vol. 10: 403-411; 411-417 y 418-427)4.

Ello incluye los métodos y formas de lucha social, así como los mecanismos e intensidades de la represión estatal. Del mismo modo, hay especial atención al tema de las condiciones de vida de los indios norteamericanos, en pleno proceso de integración forzada al país, una vez consumada la usurpación de sus territorios ancestrales (Martí, 1992, Vol. 10: 321-331 y Vol. 10: 371-379) ${ }^{5}$, o de los esclavos recientemente liberados (Martí, 1992, Vol. 10: 235-241 y Vol. 10: 313-321) ${ }^{6}$ o de las masas de inmigrantes, especialmente europeos, que llegaban año a año al país, sea para recalcar los aspectos culturales, por ejemplo (Martí, 1992, Vol. 12:

4 “Las huelgas en los Estados Unidos", La Nación, Buenos Aires, 9 Mayo 1886, y “Las grandes huelgas en los Estados Unidos", La Nación, Buenos Aires, 4 y 6 Junio 1886, entre otras.

5 "Los indios en los Estados Unidos", La Nación, Buenos Aires, 4 de Diciembre 1885, y "El problema indio en los Estados Unidos", La Nación, Buenos Aires, 18 Febrero 1886, a manera de ejemplos.

6 "Cartas de Nueva York", La Nación, Buenos Aires, 14 Junio 1885, y "Cartas De Nueva York", La Nación, Buenos Aires, 2 Diciembre 1885. 
77-87) 7 , o la relación con la difusión de idearios socialistas y anarquistas y la consiguiente actividad social (Martí, 1992, Vol. 12: 155-167 y 15-23)

Si señalamos que la "vida cotidiana" es uno de los temas centrales que cubren los trabajos de Martí, es indicativo de su interés por dar cuenta de la mentalidad que se incubaba en esa sociedad, el hecho de que le dedicara atención especial a las celebraciones de efemérides y otros actos cívicos masivos, tema que cubre entre un 5 y un $10 \%$ del total de los artículos (Martí, 1992, Vol. 10: 127-143 y Vol. 9: 85-97) ${ }^{9}$. Cabe hacer una mención especial al espacio y la atención dedicada a la inauguración de obras públicas y monumentos que trascendieron largamente a su época, constituyéndose de alguna manera en símbolos de la ciudad, como es el caso de la Estatua de la Libertad (Martí, 1992, Vol. 11: 99-119) ${ }^{10}$ y el Puente de Brooklyn (Martí, 1992, Vol. 9: 423-435)11 o el anuncio de la construcción del tren subterráneo (Martí, 1992, Vol. 11: 443-453) ${ }^{12}$.

De la misma manera, hay una presencia permanente de temas judiciales y delictivos, los que incluyen casos de corrupción política, de violencia política como el antes señalado sobre los sucesos de Chicago, de delitos comunes entre las personas, funcionamiento de las instituciones, etc., cubriendo también cerca de un $10 \%$ del total de los artículos. En cambio, temas como la Educación aparecen con mayor fuerza solamente en el período final de la estancia del autor en Nueva York, consignado en el cuarto volumen, es decir, desde 1888 a 1891. Así también ocurre con la atención hacia la presencia y problemas de la mujer en la sociedad estadounidense, tema que aparece especialmente en los artículos de dicho período (Martí, 1992, Vol. 11: 183-195)².

7 “Un funeral chino. Los chinos en Nueva York", La Nación, Buenos Aires, 16 Diciembre 1888.

8 “Cartas de Nueva York", La Nación, Buenos Aires, 20 Marzo 1885, y “Cartas desde Estados Unidos”, La Nación, Buenos Aires, 23 Agosto 1888.

9 "El día de Gracias”, La Nación, Buenos Aires, 11 Enero 1885, y “Cartas de Nueva York”, La Opinión Nacional, Caracas, 14 Noviembre 1881. Este último artículo se refiere a la celebración del Centenario de la rendición de los ingleses en Yorktown y, con ello, de la consolidación de la Independencia.

10 "Fiestas de la Estatua de la Libertad", La Nación, $1^{\circ}$ Enero 1887.

11 "El puente de Brooklyn", La América, Nueva York, Junio 1883.

12 "Ferrocarriles elevados", La Nación, Buenos Aires, 26 Junio 1888.

13 Descripción de la primera votación de las mujeres en Kansas, La Nación, Buenos Aires, 21 Mayo 1887, que se refiere como el nombre lo indica a una primera experiencia de participación de las mujeres en elecciones a nivel de un estado. 


\section{Martí, el corresponsal y el periodista}

Si examinamos el conjunto de trabajos publicados bajo la denominación de "crónicas" y reunidas en las Escenas Norteamericanas, es posible detectar una cierta complejidad formal, desde el punto de vista de los géneros periodísticos, cuestión que rebasa un tanto los límites de la crónica periodística. En primer término, es posible diferenciar claramente dos tipos de trabajos elaborados por Martí: unos de carácter magazinesco ${ }^{14}$, publicados bajo los títulos genéricos de "Cartas de Martí", o "Cartas de Nueva York", o "Cartas de Estados Unidos". Se trata de textos escritos, efectivamente, en forma epistolar y conteniendo los temas más diversos, mezclando informaciones, impresiones y juicios.

A modo de ejemplo de lo anterior podemos citar el texto publicado bajo el nombre genérico de "Cartas de Martí", por La Nación, de Buenos Aires el 14 de Agosto de 1883 y en el que el autor nos ilustra acerca de la Universidad de Harvard, de su lugar en la sociedad norteamericana y de características de su funcionamiento, para luego pasar al tema del llamado "problema indio" y terminar informando acerca de los últimos inventos de Edison y de sus polémicas con otros inventores sobre la propiedad u oportunidad de aquellos. Un segundo caso citable, en esta dirección, es el texto titulado "Cartas de Estados Unidos", publicado en La Nación, de Buenos Aires, el 28 de Febrero de 1889 y en que se nos informa de la situación del empleo en la economía estadounidense, de la actualidad política, nuevamente del "problema indio" y de la política exterior del gobierno de Estados Unidos, en relación con la situación que estaba viviendo Haití.

Hay un segundo tipo de trabajos que se sitúa en un lugar más bien contrario al anterior. Se ocupan solamente de un tema, ocupando varias páginas y tienen un título relativo al asunto en cuestión. Su estructura

14 El magazine es definido convencionalmente como un periódico ilustrado, estructurado sobre la base de numerosas secciones y generalmente de muchas páginas y de aparición semanal o mensual. Se trata de un género que es capaz de albergar en su interior en forma entremezclada crónicas, entrevistas, reportajes de actualidad, ilustraciones, avisos publicitarios, cuentos y novelas por entrega, notas de vida social, caricaturas, poemas, etc. (Martínez de Sousa, 1991). Dicho texto hace referencia a que el vocablo inglés magazine, pudiera haberse originado en la palabra francesa magasin, la cual a su vez provendría del árabe máhzan, que significa almacén. En ese sentido, el género magazinesco tendría como componente sustantivo el hecho de que en su interior es posible encontrar de todo, a la manera de un almacén. Señala también que el primer magazine sería inglés, obra del periodista Edward Cave y apareció en 1731 bajo el nombre de Gentleman's Magazine. Era de carácter mensual y tenía 42 páginas impresas a dos columnas. Durante los siglos XVIII y XIX se publicaron numerosas revistas de este tipo tanto en Europa como en los EE.UU. 
narrativa con una entrada o presentación del tema; un desarrollo y unas conclusiones o cierre, se asemeja más al reportaje interpretativo del siglo XX (Santibáñez), o si se quiere, al ensayo periodístico, ya que lo medular del texto son los datos y hechos que sustentan y justifican las opiniones y juicios que se emiten, y que conducen a las conclusiones, las que, por su parte, tienden a tener el carácter de prospectivas, tal como lo exige el reportaje moderno, en orden a señalar el curso posible de desarrollo de los hechos en el futuro inmediato.

Si bien hay numerosos ejemplos citados de este tipo de trabajos en notas anteriores, es posible mencionar como ejemplos de esta suerte de "reportajes", por lo bien logrados, a los publicados en La América, de Nueva York, en Marzo de 1883, bajo los títulos de "La cuestión arancelaria" y "En comercio, proteger es destruir", en que, dicho sea de paso, Martí expone y fundamenta su opinión favorable al libre comercio y de rechazo al proteccionismo. En un ámbito totalmente distinto, podemos citar el texto publicado en El Partido Liberal, de México, en 1887 bajo el título de "Las ferias campestres" o el publicado en La Nación, de Buenos Aires el 14 de Abril de 1887, bajo el título de "El cisma de los católicos en Nueva York".

Por último, es posible también encontrar textos unificados por un tema general, pero que contiene informaciones variadas o distintas y hechos diversos, en lo que se ha llamado también el reportaje poliecránico, en tanto mezcla articulada de temas (Becali, 1976). De modo que el trabajo periodístico que Martí desarrolla en su estancia neoyorkina, asume más bien las características de lo que ya se conocía como un Corresponsal, es decir un "periodista encargado de cubrir la información en una zona geográfica determinada, situada fuera de la sede de la publicación; puede ser una comarca o municipio, la capital del país o el extranjero" (Martínez de Souza 127).

Sigue señalando la definición que el trabajo del Corresponsal es el de procurarse y transmitir informaciones, especialmente aquellas relativas a aspectos no cubiertos por las agencias de noticias o, y esto es probablemente lo más distintivo especialmente en el caso de Martí, dar su versión particular de los hechos, aunque éstos fueran conocidos por otros medios. Dicho de otro modo, en la segunda mitad del siglo XIX aparece esta figura profesional, propiamente periodística, que implica alguien que está en un lugar al que la gran mayoría de sus potenciales 
lectores no puede acceder para mirar los hechos, sentirlos y pensarlos por ellos, en una época donde el rol estrictamente mediador del periodista cobra plena vigencia y legitimidad social, dada la imposibilidad de una masa creciente de lectores de acceder directamente a la experiencia de los hechos (Gomis, 1991). La labor de Martí calza muy exactamente con esta figura del Corresponsal, a la luz de lo que hemos señalado respecto a la forma y contenido de sus trabajos, ya que: "Normalmente, el corresponsal, representante único de su periódico en su lugar de residencia, carece de una especialización concreta, por lo cual cubre indistintamente todo tipo de acontecimientos: políticos, deportivos, económicos, artísticos, científicos, etc." (Martínez de Souza 132).

La actividad del Corresponsal, en un contexto donde imperaba la palabra escrita en el campo de la prensa se fue perfilando desde la mitad del siglo XIX y, en especial, alrededor de hechos bélicos. Es por demás conocido el caso de William Howard Russel, corresponsal del Times, de Londres, en la Guerra de Crimea (1853-1855) y el movimiento de opinión contrario a la guerra generado alrededor de sus informaciones o el de Archibald Forbes en la Guerra Franco-prusiana de 1870-1871. Es también lo sucedido en la Guerra Civil de Estados Unidos (1861-1865) y, en el caso de América Latina, lo ocurrido en la Guerra del Pacífico (1879-1883).

\section{Conclusión: "Y la prensa, la reina nueva, la amable reina poderosa"15}

Finalmente, a la luz delos textos que Martí, en su oficio de Corresponsal, le dedica a lo que observa del desarrollo de la prensa estadounidense, es posible afirmar que tiene una visión bastante completa y profunda de los procesos que está viviendo la actividad periodística en esos momentos y que, justamente, tienen a Estados Unidos como uno de los lugares donde aquellas transformaciones están marcando pauta. De la misma forma, pareciera que en Martí hay una plena claridad acerca del rol del profesional periodista que se está consolidando. En ese sentido, en sus primeros años como Corresponsal afirmaba el rol de la prensa proclamando, “¡Oh, el periódico! ¡lente inmensa, que en este siglo levanta y refleja con certidumbre beneficiosa e implacable las sinuosidades

15 "Cartas de Nueva York", La Opinión Nacional, Caracas, 26 Noviembre 1881 /(Martí, 1992, Vol.10: 112) 
lóbregas, las miserias desnudas, las grandezas humildes, las cumbres resplandecientes de la vida!" (Martí, 1992, Vol. 9: 412) ${ }^{16}$.

Sin embargo, a medida que avanza el tiempo, su mirada y su opinión se van complejizando al percatarse de los heterogéneos procesos que subyacen al panorama superficial de la existencia de una amplia y variada oferta periodística, haciendo ver a sus lectores de Latinoamérica las características que asume la competencia cada vez más fuerte en el naciente mercado informativo. Destaca así:

la lucha empeñadísima de los periódicos de la mañana que a ocho centavos se siguen vendiendo y cada día inventan métodos con que arrebatar sus lectores a los diarios rivales, entre cuyos métodos el de escribir con ligereza y de burla sobresale y prima, por ser la necedad y frívola disposición condiciones que alcanzan mayoría en lo común de los públicos. (Martí, 1992, Vol. 10: 49) ${ }^{17}$

Más específicamente, días antes había hecho referencia al uso de cierta prensa dirigida a la creciente masa de inmigrantes, en el marco del caciquismo y corrupción política, al denunciar que "pena da a veces ver cómo cortejan estos periódicos a la muchedumbre: -le halagan sus gustos; le sacrifican la propia cultura; se fingen por complacer, vulgares y brutales; se echan encima por la esperanza de la propina el arreo servil y la sonrisa dolorosa de los lacayos" (Martí, 1992, Vol. 10: 41) ${ }^{18}$.

No obstante, lo anterior no excluye el valor que un periodismo centrado en abastecer de informaciones a un público cada vez más masivo y demandante, puede tener en el marco de procesos modernizadores profundos y complejos, señalando que:

ya el periodista ha de abarcar (...) la moderna vida múltiple, en todas sus formas, cómo ruge en las fraguas, cómo se transforma en el comercio y viaja, cómo se ideifica en la literatura y en la política, cómo se sublima y colorea en las artes. El periodista ha de saber, desde la nube hasta el microbio. (Marti, 1992, Vol. 10: 235$)^{19}$ 
En ese sentido, se hace cargo de la nueva concepción de periodista que está surgiendo como depositario de unas técnicas y unas competencias profesionales capaces de instalarlo como testigo de la historia y mediador social, al señalar que "estén las noticias bien redactadas, de modo que lo que se diga sea el hecho cierto, que es lo único que la pluma ha de escribir, aunque vaya contra la simpatía propia u opinión" (Martí, 1992, Vol. 12: 471$)^{20}$.

Específicamente destaca en esa dirección el papel desarrollado por The Evening Sun, periódico dirigido a un público popular y masivo, a quien define como: "el diario de la tarde de a centavo donde siguen juntándose con arte admirable la viveza en la noticia y la literatura, la literatura gráfica y viva en el estilo, no aquella pompa clásica, jerga de libros y hueca imaginería de los diarios inútiles y académicos" (Martí, 1992, Vol. 11: 196) ${ }^{21}$, entusiasmo que lo lleva a afirmar a fines de ese mismo año que el The Evening Sun "como diario es una verdadera maravilla, y el más despierto y artístico que se escribe tal vez en lengua alguna" (Marti, 1992, Vol. 11: 327) ${ }^{22}$. Cabe recordar que The Evening Sun fue fundado en 1833 por Benjamín Day, el que había comenzado trabajando como tipógrafo. A un precio de dos centavos tuvo un rápido éxito llegando a una tirada de 19.000 ejemplares en 1835. En la época de Martí y con nuevos dueños, pero sin cambiar esencialmente su perfil, la tirada se había elevado a unos 100.000 ejemplares diarios (Weill 149 y 201).

De todos modos, lo anterior no implica que Martí fuera ciego al hecho de que los procesos de modernización de la prensa en Estados Unidos, y como poco después ocurriría en América Latina conducían casi inevitablemente a la concentración de la propiedad, cuestión coherente con los procesos de conformación de elites de poder, como sería predominante en las décadas siguientes. Dicha cuestión se le va haciendo cada vez más evidente, a medida que avanzan los años de su estadía en Nueva York, lo que lo llevó a afirmar en 1889 que, "la prensa en que los ricos tienen puesta toda la mano, con raras excepciones, defiende a los ricos" (Marti, 1992, Vol. 12: 145) ${ }^{23}$.

20 “Cartas de Estados Unidos", La Nación, Buenos Aires, 24 Diciembre 1890.

21 "El monumento de la prensa. Los periodistas de Nueva York", La Nación, Buenos Aires, 28 Julio 1887.

22 “Cosas del otro mundo", La Nación, 29 Diciembre 1887.

23 "Cartas de Estados Unidos", La Nación, Buenos Aires, 30 Marzo 1889. 
En definitiva, las Escenas Norteamericanas nos muestran a un Martí plenamente posesionado de su función de Corresponsal que está presenciando e interpretando el devenir de la sociedad estadounidense por un cierto público latinoamericano y en el lugar de él, con la convicción de que ello implicaba el desarrollo de unas estrategias escriturales y narrativas nuevas y distintas que se centran en la transmisión de informaciones relevantes para un público masivo. Por ello, es que podía afirmar sobre su trabajo que "El arte de escribir ¿no es reducir? La verba mata sin duda la elocuencia (...) Hay tanto que decir, que ha de decirse en el menor número de palabras posible: eso sí, que cada palabra lleve ala y color" (Martí, 1992, Vol. 11: 196) ${ }^{24}$.

24 "El monumento de la prensa. Los periodistas de Nueva York", La Nación, Buenos Aires, 28 Julio 1887. 


\section{Referencias bibliográficas}

Becali, Ramón. Martí corresponsal. La Habana: Orbe, 1976.

Benítez, Jorge. José Martí y Chile. Santiago de Chile: LOM Ediciones, 1995.

Berman, Marshall. Todo lo sólido se desvanece en el aire. La experiencia de la modernidad. México: Siglo XXI, 1990.

Gomis, Lorenzo. Teoría del periodismo. Como se forma el presente. Barcelona: Paidós, 1991.

Martí, José. Obras Completas. La Habana: Ediciones de Ciencias Sociales, 1992.

Martín Vivaldi, Gonzalo. Géneros periodísticos. Madrid: Paraninfo, 1993.

Martín Barbero, Jesús y Muñoz, Sonia. Televisión y Melodrama. Bogotá: Tercer Mundo, 1992.

Martínez Albertos, Jesús. Redacción Periodística. Barcelona: ATE, 1974.

Martínez de Souza, José. Diccionario de Información, Comunicación y Periodismo. Madrid: Paraninfo, 1991.

Ramos, Julio. Desencuentros de la modernidad en América Latina. México: Fondo de Cultura Económica, 1989.

Rotker, Susana. Fundación de una escritura: las crónicas de José Martí. La Habana: Casa de las Américas, 1992.

- La invención de la crónica. México: Fondo Cultura Económica, 2005.

Santa Cruz A., Eduardo. "Cuestión de patricios y letrados. Prensa y espacio público en América Latina y Chile (18201850)". Mapocho 66 (2009): 193-221.

Santibañez, Abraham. Periodismo Interpretativo. Santiago de Chile: Ercilla, 2007.

Schulman, Iván. El proyecto inconcluso. La vigencia del modernismo. México: Siglo XXI, 2002.

Weill, Georges. El periódico. Orígenes, evolución y función de la prensa periódica. México: UTEHA, 1994. 